\title{
Effects of Social Support on Athletes' Psychological Well-Being: The Correlations among Received Support, Perceived Support, and Personality
}

\author{
Eriko Katagami' ${ }^{1}$ Hironobu Tsuchiya ${ }^{2}$ \\ ${ }^{1}$ Graduate School of Sport Sciences, Osaka University of Health and Sport Sciences, Osaka, Japan \\ ${ }^{2}$ Osaka University of Health and Sport Sciences, Osaka, Japan \\ Email:214d01@ouhs.ac.jp
}

How to cite this paper: Katagami, E., \& Tsuchiya, H. (2016). Effects of Social Support on Athletes' Psychological Well-Being: The Correlations among Received Support, Perceived Support, and Personality. Psychology, 7, 1741-1752.

http://dx.doi.org/10.4236/psych.2016.713163

Received: October 2, 2016

Accepted: November 21, 2016

Published: November 24, 2016

Copyright $\odot 2016$ by authors and Scientific Research Publishing Inc. This work is licensed under the Creative Commons Attribution International License (CC BY 4.0).

http://creativecommons.org/licenses/by/4.0/

\begin{abstract}
The current study aimed to examine the impact of received support and perceived support on athletes' psychological well-being. Furthermore, correlations between received support, perceived support, and personality were investigated. Two hundred and thirty-nine Japanese university student athletes $(\mathrm{M}$ age $=19.69 \pm 1.01$ years) completed the questionnaires regarding social support, psychological well-being, and personality. The results indicated that received support was positively correlated with athletes' psychological well-being, while perceived support was not found to be a predictor of psychological well-being. Furthermore, it was demonstrated that received support and perceived support were positively correlated with each other. In addition, the results indicated that there was no relationship between received support and positive self-schema, whereas perceived support was positively correlated with positive self-schema. In conclusion, received support can be a salient predictor of athletes' psychological well-being.
\end{abstract}

\section{Keywords}

Social Support, Psychological Well-Being, Athletes, Personality, Schema

\section{Introduction}

Social support has also been recognized a significant factor in maintaining physical health (Malinauskas, 2008) and psychological health (Holt \& Hoar, 2006). Social support from coaches, teammates, family, friends, and staff is considered to affect athletes' cognitive, emotional, and behavioural aspects in a positive manner (Rees, 2007). Given that social support has been broadly reported to be an essential factor for athletes' success, sport psychology researchers have endeavored to clarify the functional aspects of 
social support (Rees \& Hardy, 2000). Psychology literature had shown that the perception of available support can be a better predictor of health or well-being outcomes (Sarason, Pierce, \& Sarason, 1990); researchers in sport psychology had also focused more on the perception of available support, which is called perceived support. It was shown that perceived support plays a significant role both for sport performance (Rees \& Freeman, 2010; Rees \& Freeman, 2007) and psychological health outcomes, such as low levels of burnout (Tsuchiya, 2012). As such, perceived support was commonly measured in research examining social support within a sport context.

In addition, to the perception of social support, more recently, researchers have moved their focus onto social support actually exchanged, which is called received support. Received support is defined as the actual receipt of social support reported by a recipient (Rees, 2007). Received support has been reported, mostly in the interviews with athletes, as a significant factor in athletes' self-confidence (Hays, Maynard, Thomas, \& Bawden, 2007), performance improvement (Rees \& Freeman, 2010), in dealing with negative psychological states due to injury in sport (Carson \& Poleman, 2012), competitive stressors (Weston, Thelwell, Bond, \& Hutching, 2009), and organizational stressors (Kristiansen \& Roberts, 2010). As such, examining received support with qualitative methods provides researchers with the enriched information necessary to understand the social support process; however, it should be cautioned that most findings were concluded from the data with a small number of athletes. As the sole reliance on the findings gained by small sample size has been criticized (Culver, Gilbert, \& Trudel, 2003), it should be avoided to generalize the importance of receipt of social support without further research with a larger sample size. Therefore, an investigation of received support with quantitative research methods would be needed in order to confirm the importance of received support in athletes' healthy life as an athlete.

Although the use of a sport-specific context of measurement is encouraged to develop social support research to examine the effect of the receipt of support in sport (Holt \& Hoar, 2006), the number of research studies that have examined received support with quantitative methods is still relatively few. Recently, Freeman, Coffee, Moll, Rees, and Sammy (2014) developed the sport-specific measurement for received support, and found that certain types of received support positively predicted athletes' self-confidence within a pre-competition time period. More specifically, the receipt of emotional and esteem support was found to be as a predictor of athletes' self-confidence before a competition; this suggests that athletes should be provided with these types of support to enhance their self-confidence. It seems that the receipt of social support would be helpful for improving factors for performance enhancement.

Nevertheless, the reported beneficial results of received support gained through qualitative research do not merely pertain to sport performance outcomes, but also to a wider range of outcomes that relate to psychological health and well-being. For instance, research demonstrated that the receipt of sufficient support from others is one of the most important features of highly successful athletes that relates to their entire athletic career (Morgan \& Giacobbi, 2006), and the receipt of support from coaches contributes to the development of a pleasant coach-athlete relationship (Hassell, Sabis- 
ton, \& Bloom, 2010), which may lead to athletes' satisfaction with their sport environment. As such, the effectiveness of received support should also be demonstrated in relation to athletes' psychological health outcomes as well, not only with sport performance outcomes. These examinations would further confirm the significance of social support for athletes in more general manner. Even though the achievement of high performance is a significant aim for participating in a sport (Rees, 2007), maintaining physical and psychological health is also salient, in terms of the athletes' success in regard to their whole life. Thus, the clarification of effective social support in relation to such psychological health and well-being outcomes using quantitative methods would allow for the development of social support literature.

One strong benefit of the research on received support is that it enables to measure the relatively precise type of support behaviour that the athlete actually received from others and its effects, which leads to further understanding of more functional aspects of social support compared to perceived support. Despite the evidence that shows the importance of perceiving available support in on athletes' health, perceived support is sometimes questioned to recognize as a result of social support. This is because some researchers argued that perceived support is possibly a reflection of the one's individual's personality factor (Tsuchiya, 2012). Perceived support is measured by asking about one's perception of the availability of social support, which may be possible to reflect one's personality. In fact, there is an evidence that reported availability of social support did not alter even the person's support network environment changed (Newcomb, 1990), which suggest that it may be difficult to use perceived support to examine the outcome of social support exchange. Received support, on the other hand, is commonly measured by asking about the frequency of actually provided social support by others, with a questionnaire (e.g. Freeman, Coffee, Moll, Rees, \& Sammy, 2014). Thus, it seems that measuring received support should be more appropriate to understand the impact of the actual support behaviours that were received by athletes. Therefore, the examination to ensure if received support is less related to one's personality factor than perceived support, would be needed to prove that received support is the more appropriate to examine the social support effectiveness.

The examination of the impact of received support on psychological well-being would contribute to the literature in order to suggest the significance of the receipt of social support in sport. In addition, further investigation of received support in relation to perceived support would be useful for further clarification of social support mechanisms, as researchers recommend to the use of incorporate measures of received support and perceived support within the same study (Bianco \& Eklund, 2001). Moreover, the relationship of social support and personality factors should be clarified to discuss social support, not as a reflection of personality, which is commonly argued in literature (Lakey \& Cohen, 2000). The first aim of the current study was, therefore, to investigate the relationship between received, perceived support, and recipients' personality. In addition, we also examined the impact of received support, and perceived support on psychological well-being. 


\section{Methods}

\subsection{Participants}

Two hundred and thirty-nine university student athletes $($ male $=126$, female $=113$ ) from two Japanese universities volunteered to participate in this study. The average age of the participants was $19.69 \pm 1.01$ years. The athletes played either individual sports (e.g., swimming, track and field, gymnastics, Judo, etc.), or team sports (e.g., football, basketball, lacrosse, baseball, etc.). The participants had completed for a mean of $4.31 \pm$ 2.64 of participation in the sport.

\subsection{Procedures}

After approval was obtained from the first author's university ethics committee, participants were recruited from university lectures for undergraduates. Participants were provided with a letter that contained a brief explanation of the study, and were informed that they were free to withdraw at any given time without prejudice. They were then asked to complete the informed consent form. No participants chose to withdraw.

\subsection{Measures}

\subsubsection{Japanese Version of the Athlete Received Support Questionnaire} (The ARSQ-J)

The ARSQ-J (Katagami \& Tsuchiya, 2015) was used to measure athletes' received support. The participants were asked to rate the frequency of received support over the previous week (0: none, 1: once or twice, 2: three or four times, 3: five or six times and 4: more than seven times), along with 22 items that concerned emotional (five items: e.g., "cheer you up"), esteem (five items: e.g., "reinforce the positives"), informational (six items: e.g., "give you advice about what to do"), and tangible (six items: e.g., "help your training") support. For each item, the participants rated the frequency of support they received, respectively, from others in own team (i.e. coaches, teammates, and staffs) over the previous week. Higher scores indicated a higher frequency of received support.

\subsubsection{The Social Support Scales for Athletes (The SSSA)}

The SSSA (Tsuchiya, 2012) was used to measure the perceived availability of social support from others. The questionnaire contained five items that included "Do you have somebody who provides you with useful information?". The participants responded to each items on the five-point Likert scale that ranged from 1 (not at all) to 5 (extremely). Higher score indicated higher levels of perceived available social support.

\subsubsection{The Psychological Well-Being Scale (The PWS)}

The PWS (Nishida, 2000) was used to measure psychological well-being. The questionnaire consists of six dimensions of psychological well-being: self-acceptance (positive evaluations of self and one's past life), personal growth (a sense of continued growth and development as a person), purpose in life (the belief that one's life is purposeful and meaningful), positive relationship with others (the possession of quality relationship with others), environmental mastery (the capacity to manage effectively 
one's life and surrounding world), and autonomy (a sense of self-determination). The participants rated to what extent that each item was applicable, on a five-point Likert scale ranging from 1 (not at all) to 5 (extremely). Higher scores indicated a higher levels of perceived psychological well-being.

\subsubsection{The Japanese Version of the Brief Core Schema Scale (JBCSS)}

The JBCSS (Yamauchi, Sudo, \& Tanno, 2009) was used as a personality measurement. The scale consists of four dimensions: Positive Self (PS), Negative Self (NS), Positive Others (PO), and Negative Others (NO). In the current study, we used PS and PO to examine the levels of one's schema regarding self and others. Higher scores indicated a higher perception of one's positive schema on the self and others. The participants rated these on a five-point Likert scale, from 1 (not at all) to 5 (extremely).

\subsubsection{Demographic Data}

Demographic information including age, gender, years of sport experience, and competitive level in the team were gathered. The competitive level in the team was chosen from the following possible answers: "a regular member", "a bench member", "out of bench" and "others (including injured)".

\subsection{Data Analyses}

To describe the distribution pattern tendency of the variables, the mean, standard deviation, and ranges were calculated for received support and perceived support. Internal consistency of each the scales were examined with Cronbach's alpha. Subsequently, correlation analyses and multiple regression analyses were conducted using IBM SPSS Statistics 21.0.

\section{Results}

\subsection{Relationship between Received Support, Perceived Support, and Personality}

The internal consistency was acceptable both in received support $(\alpha=.96)$ and perceived support $(\alpha=.83)$. The means, standard deviations, and correlations between received support and perceived support were shown in Table 1 . It was shown that received support and perceived support were positively correlated with each other $(r=.70$, $p<.01)$.

The correlation analysis between received support, perceived support and personality was conducted (Table 2). It was indicated that the athletes' positive other-schema was positively correlated both with received support $(r=.36, p<.01)$ and perceived support $(r=.56, p<.01)$. Positive self-schema was correlated only with perceived support $(r=.24$, $p<.01)$, and not correlated with received support $(r=.06$, n.s. $)$.

\subsection{Impacts of Received Support and Perceived Support on Psychological Well-Being}

The correlations between received support, perceived support and psychological well- 
Table 1. Descriptive statistics of received support and perceived support.

\begin{tabular}{|c|c|c|c|c|c|c|c|c|c|c|c|c|c|}
\hline & & $M$ & $S D$ & & 1 & 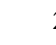 & & & & trat & & 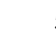 & \\
\hline 1 & emotional support & 18.55 & 4.97 & - & & & & & & & & & \\
\hline 2 & esteem support & 18.49 & 5.06 & .88 & $* *$ & - & & & & & & & \\
\hline 3 & informational support & 22.92 & 5.68 & .78 & $* *$ & .79 & $* *$ & - & & & & & \\
\hline 4 & tangible support & 21.14 & 5.76 & .75 & $* *$ & .76 & ** & .84 & ** & - & & & \\
\hline 5 & $\begin{array}{c}\text { Received support } \\
\text { (ASRQ-J) }\end{array}$ & 81.51 & 19.66 & .92 & $* *$ & .92 & $* *$ & .93 & $* *$ & .91 & $* *$ & - & \\
\hline 6 & $\begin{array}{c}\text { Perceived support } \\
\text { (SSSA) }\end{array}$ & 14.92 & 3.41 & .63 & $* *$ & .66 & ** & .63 & ** & .65 & ** & .70 & $* *$ \\
\hline
\end{tabular}

$\mathrm{n}=239, p<.05^{*}, p<.01^{* *}$.

Table 2. Correlations between social support and core schema.

\begin{tabular}{ccccccc}
\hline & $M$ & $S D$ & \multicolumn{2}{c}{ Received } & \multicolumn{2}{c}{ Perceived } \\
Positive self & 7.85 & 4.15 & .06 & .24 & $* *$ \\
Positive others & 9.64 & 4.65 & .36 & $* *$ & .56 & $* *$ \\
\hline
\end{tabular}

$\mathrm{n}=239, p<.05^{*}, p<.01^{* *}$.

being were indicated in Table 3. The results showed that an aggregate psychological well-being was positively correlated with received support $(r=.31, p<.01)$ and perceived support $(r=.31, p<.01)$. Specifically, it was shown that there was a positive correlation between "personal growth" and received support $(r=.30, \mathrm{p}<.01)$ and perceived support $(r=.28, p<.01)$. Also, "positive relationship with others" was positively correlated with received support $(r=.44, p<.01)$ and perceived support $(r=.51, p<.01)$.

To examine the effect of received support and perceived support on psychological well-being, multiple regression analysis was conducted. The results showed that received support positively predicted athletes' psychological well-being $(\beta=.36, p<.01)$, while perceived support did not significantly predict it when we assumed psychological well-being as an outcome variable $(\beta=.12$, n.s. $)$. The model was statistically significant $\left(R^{2}=.12, p<.01\right)$.

\section{Discussion}

The first aim of the current study was to 1) investigate the correlations between received, perceived support and personality, and 2) examine the impact of received support and perceived support on psychological well-being.

\subsection{Relationship between Received, Perceived Support, and Personality}

In general psychology, it has been considered that the correlations between perceived and received support is relatively low (Dunkel-Shetter \& Bennett, 1990). However, in a sport context, it has been shown that perceived support and received support were moderately correlated (Rees \& Freeman, 2007). Consistent with this, in the current 
Table 3. Correlations between perceived and received support and psychological well-being.

\begin{tabular}{|c|c|c|c|c|c|c|c|c|c|c|c|c|c|c|}
\hline \multirow[b]{2}{*}{ Personal growth } & \multirow{2}{*}{$\begin{array}{c}M \\
33.74\end{array}$} & \multirow{2}{*}{$\begin{array}{c}S D \\
4.75\end{array}$} & \multicolumn{2}{|c|}{ Emotional } & \multicolumn{2}{|c|}{ Esteem } & \multicolumn{4}{|c|}{ Informational Tangible } & \multicolumn{2}{|c|}{ ARSQ } & \multicolumn{2}{|c|}{ SSSA } \\
\hline & & & .29 & $* *$ & .29 & $* *$ & .32 & $* *$ & .22 & * & .30 & $* *$ & .28 & ** \\
\hline Purpose in life & 24.08 & 5.71 & .12 & & .13 & & .18 & & .18 & * & .17 & & .10 & \\
\hline Autonomy & 25.35 & 4.64 & .00 & & -.02 & & -.10 & & .03 & & -.01 & & -.02 & \\
\hline Self-acceptance & 21.34 & 4.40 & .06 & & .18 & $* *$ & .09 & & .15 & * & .14 & $*$ & .11 & \\
\hline $\begin{array}{c}\text { Environmental } \\
\text { mastery }\end{array}$ & 20.89 & 3.34 & .12 & & .14 & & .18 & $* *$ & .22 & * & .16 & & .31 & $* *$ \\
\hline $\begin{array}{l}\text { Positive } \\
\text { relationships } \\
\text { with others }\end{array}$ & 22.51 & 4.04 & .40 & $* *$ & .47 & $* *$ & .40 & $* *$ & .38 & $* *$ & .44 & $* *$ & .51 & $* *$ \\
\hline PWB & 149.65 & 17.11 & .24 & * & .28 & $* *$ & .30 & $* *$ & .30 & $* *$ & .31 & $* *$ & .31 & $* *$ \\
\hline
\end{tabular}

$\mathrm{n}=239, p<.05^{*}, p<.01^{* *}$.

study, received and perceived support were positively correlated, which suggested a positive correlational relationship between athletes' perception of and actual receipt of social support. Both perceived and received support are considered to be a salient in sport; however, these two aspects should be clearly distinguished in order to avoid the misunderstanding of social support in an actual sport setting (Rees \& Freeman, 2007). In this study, received support and perceived support were differentially correlated with personality factors, suggesting that these two aspects possibly possess different functions.

In the current study, solely perceived support was positively correlated with positive self-schema. This suggests that reported perceived support may closely relate to one's schema, implying that social support measured using perceived support depends on the perception of themselves, rather than the outcomes of social support. Despite the fact that numerous studies found a relationship between social support and positive psychological health outcomes, there has been an argument discussing that the measurement of social support using perceived support does not purely reflect the effect of social support exchange, but it does not reflect the recipient's personality (Lakey \& Cohen, 2000). It is explained as an artefact model, which indicates that personality influences both social support and psychological health and well-being, resulting in spuriously correlations between perceived support and outcomes (Hashimoto, 2005). In fact, it is reported that the level of perceived support was not altered, even though one's environmental changes occurred (Newcomb, 1990); which is difficult to deny that the perceived support merely reflects one's personality.

On the other hand, the results demonstrated that received support did not significantly correlate with positive self-schema, suggesting that social support measured using received support may be less reflective of one's personality factor. It has been shown that received support is less related to one's cognition and personality variables than perceived support (Lakey \& Cassady, 1990). The results lead us to conclude that the examination with received support is more appropriate to investigate the actual social 
support exchange and its outcomes, as it is suggested the measurement of received support would be helpful to specify the effectiveness of social support (Fukuoka, 1999). The importance of social support has been identified within a various ranges of athletes, including youth athletes (e.g. Van Yperen, 1998) to adolescent stage athletes (e.g. Kristiansen \& Roberts, 2010). Moreover, social support has been identified at and a variety of competitive levels, from the university level (Tsuchiya, 2012) to the professional (Fletcher \& Sarkar, 2012) or elite level (Hassell, Sabiston, \& Bloom, 2010; Hays, Maynard, Thomas, \& Bawden, 2007). As such, the identification of an effective social support would help athletes' potential support providers. An examination with received support should be encouraged to identify the actual supportive behaviour.

\subsection{Impacts of Received Support and Perceived Support on Psychological Well-Being}

The results of the current study suggest that received support is a better predictor of athletes' psychological well-being. In general psychology, received support has been recognized to be as less significant, since it was suggested that the relationship between received support and health was weaker than that of perceived support (Dunkel-Shetter \& Bennett, 1990). However, more recently, some researchers in social psychology suggested that received support has been of more focus, specifically in relation to the well-being factors such as one's satisfaction (Finch et al., 1997). In a sport context, Holt and Hoar (2006) questioned if perceived support is truly a better predictor of one's health than received support. Moreover the need for research in received support is encouraged (Rees, 2007). Recently, as the correlations between received support and self-confidence has been reported (Freeman, Coffee, Moll, Rees, \& Sammy, 2014), the benefits of the receipt of support has been demonstrated in relation to sport performance. The results of the current study added to the literature that social support is beneficial not only for sport performance outcomes such as self-confidence, but also for psychological well-being.

It is encouraged that athletes' significant others to provide support to their athletes (Rees, 2007). Given that the effectiveness of received support was indicated in a broad sense, the significance of providing support when it needed should be known to athletes' potential support providers such as coaches, staff and parent. In the case of athletes' struggling with a difficult situation to cope with, the provision of social support from coaches, teammates, and family is considered to be an indispensable in one's athletic life; specifically, when an athlete is dealing with an adverse situation (Morgan \& Giacobbi, 2006). It seems that beneficial support should be provided to athletes in order to prevent an athletes' dropout or serious anxiety. As the receipt of support may not be considered as a sign of weakness (Hardy, Jones, \& Gould, 1996), it might be important to notify athletes to be proactive to utilise the social support available.

Although the current study demonstrated that received support can be a predictor of psychological well-being, it should be recognised that the effectiveness of social support can be determined by various factors, such as the types, timing, and provider of support 
(Rees, 2007). As it is reported that not all supportive behaviour is beneficial to the recipient (Reinhardt, 2006), the effectiveness of social support should be well-examined and carefully conveyed to athletes' potential support providers. The influence of these factors should be examined to enhance the decent understanding of social support behaviour in a sport setting. Specifically, the effective social support by its providers should be considered because there is a number of studies reporting inappropriate support from coaches in a sport setting (e.g. McKay, Niven, Lavallee, \& White, 2008). The coach-athlete relationship is considered to be the most important social interaction in a sport context (Megeau \& Vallerand, 2003). The social support exchange between the coach and athlete plays a significant role in fostering the coach-athlete relationship (Hassell, Sabiston, \& Bloom, 2010). It seems that inappropriate support from a coach might prevent athletes' development of sport performance and psychological well-being. Further research to identify the coaches' effective support would be useful for sport psychology practitioners or consultants who work with coaches. Similarly, it has been suggested that teammates or peers can also be significant providers of support for athletes (Vazou, Ntoumanis, \& Duda, 2006). Sport psychology researchers should clarify an effective support behavior among teammates, which would develop a social support based team-building intervention. Further research should examine the differences between the effectiveness of social support by providers on the benefits of social support to athletes' psychological health or well-being.

Some limitations should be noted. First, a causal-relationship is not deduced in this study due to the correlational nature of analysis. Second, since the participants in the current study were university student athletes, further research should examine within a wider range of samples to see if the findings are relevant to athletes in general. Third, although we used a core schema scale to measure one's personality factor, it should be reminded that schema is one aspects of a personality factor. Sarason, Sarason and Gurung (2001) proposed three domains of personality factors in relation to social support: temperament (e.g. neuroticism), cognitive (e.g. locus of control, hardiness, self-efficacy), and schema (e.g. support schema) factors. Further research should be conducted to confirm the relationship between social support and personality with other variables.

\section{Conclusion}

The current study aimed to examine the correlations between received support, perceived support, and personality. In the present study, we found that received support and perceived support were positively correlated with each other. However, it was indicated that they were differentially correlated with personality factors. Received support was not correlated with positive self-schema, while perceived support was positively correlated with. Furthermore, the impact of received and perceived support on athletes' psychological well-being was investigated. The current study highlighted that received support may be a predictor of psychological well-being, suggesting that the receipt of social support may be a key factor in athletes' psychological well-being not only for sport performance outcomes. Further examinations of received support with other 
moderating effects would be useful to clarify the function of social support behavior in order to identify the effective support, which should be shared with athletes' potential support providers such as coaches, parents, and staffs.

\section{References}

Bianco, T., \& Eklund, R.C. (2001). Conceptual Considerations for Social Support Research in Sport and Exercise Settings: The Case of Sport Injury. Journal of Sport and Exercise Psychology, 23, 85-107. http://dx.doi.org/10.1123/jsep.23.2.85

Carson, F., \& Polman, R. (2012). Experiences of Professional Rugby Union Players Returning to Competition Following Anterior Cruciate Ligament Reconstruction. Physical Therapy in Sport, 13, 35-40. http://dx.doi.org/10.1016/j.ptsp.2010.10.007

Culver, D. M., Gilbert, W. D., \& Trudel, P. (2003). A Decade of Qualitative Research in Sport Psychology Journals: 1990-1999. The Sport Psychologist, 17, 1-15.

http://dx.doi.org/10.1123/tsp.17.1.1

Dunkel-Schetter, C., \& Bennett, T. (1990). Differentiating the Cognitive and Behavioral Aspects of Social Support. In B. R. Sarason, I. G. Sarason, \& G. R. Pierce (Eds.), Social Support: An Interactional View (pp. 267-296). New York: Wiley.

Finch, J. F., Barrera, M., Okun, M. A., Bryant, W. H. M., Pool, G. J., \& Snow-Turek, A. L. (1997). The Factor Structure of Received Social Support: Dimensionality and the Prediction of Depression and Life Satisfaction. Journal of Social and Clinical Psychology, 16, 323-342. http://dx.doi.org/10.1521/jscp.1997.16.3.323

Fletcher, D., \& Sarkar, M. (2012). A Grounded Theory of Psychological Resilience in Olympic Champions. Psychology of Sport and Exercise, 13, 669-678. http://dx.doi.org/10.1016/j.psychsport.2012.04.007

Freeman, P., Coffee, P., Moll, T., Rees, T., \& Sammy, N. (2014). The ASRQ: The Athletes' Received Support Questionnaire. Journal of Sport and Exercise Psychology, 36, 189-202. http://dx.doi.org/10.1123/jsep.2013-0080

Fukuoka, Y. (1999). Reciprocity of Receiving and Giving Support and Emotional States in Friendships: From the Perspectives of Perceived and Enacted Supports. Annual Report of University of Shizuoka, Hamamatsu College, 13, 57-70.

Hardy, L., Jones, G., \& Gould, D. (1996). Understanding Psychological Preparation for Sport: Theory and Practice of Elite Performers. Wiley: Chichester.

Hashimoto, T. (2005). Sutoresu to taijinkankei: [Stress and Interpersonal Relationships]. Kyoto: Nakanishiya syuppan. (In Japanese)

Hassell, K., Sabiston. C. M., \& Bloom, G. (2010). Exploring the Multiple Dimensions of Social Support among Elite Female Adolescent Swimmers. International Journal of Sport Psychology, 41, 340-359.

Hays, K., Maynard, I., Thomas, O., \& Bawden, M. (2007). Sources and Types of Confidence Identified by World Class Sport Performers. Journal of Applied Sport Psychology, 19, 434-456. http://dx.doi.org/10.1080/10413200701599173

Holt, N. L., \& Hoar, S. D. (2006) The Multidimensional Construct of Social Support. In S. Hanton, \& S. D., Mellalieu (Eds.), Literature Review in Sport Psychology. London: Nova Science Publishers.

Katagami, E., \& Tsuchiya, H. (2015). Development of the Japanese Version of the Athlete Received Support Questionnaire. Paper Presented at Japanese Society of Sport Psychology, the 42nd Annual Meeting, Fukuoka, 37. (In Japanese) 
Kristiansen, E., \& Roberts, G. C. (2010). Young Elite Athletes and Social Support: Coping with Competitive and Organizational Stress in "Olympics" Competition. Scandinavian Journal of Medicine and Science in Sports, 20, 686-695. http://dx.doi.org/10.1111/j.1600-0838.2009.00950.x

Lakey, B., \& Cassady, P. B. (1990). Cognitive Processed in Perceived Social Support. Journal of Personality and Social Psychology, 50, 337-343. http://dx.doi.org/10.1037/0022-3514.59.2.337

Lakey, B., \& Cohen, S. (2000). Social Support and Theory. In S. Cohen, L. G. Underwood, \& B. H. Gottlieb (Eds.), Social Support Measurement and Intervention: A Guide for Health and Social Scientists (pp. 29-52). New York: Oxford University Press. http://dx.doi.org/10.1093/med:psych/9780195126709.003.0002

Malinauskas, R. (2008). College Athletes' Perception of Social Support Provided by Their Head Coach before Injury and after It. Journal of Sports Medicine and Physical Fitness, 48, 107-112.

McKay, J., Niven, A. G., Lavallee, D., \& White, A. (2008). Sources of Strain among Elite UK Track Athletes. The Sport Psychologist, 22, 143-163. http://dx.doi.org/10.1123/tsp.22.2.143

Megeau, G. A., \& Vallerand, R. J. (2003). The Coach-Athlete Relationship: A Motivational Model. Journal of Sports Sciences, 21, 883-904. http://dx.doi.org/10.1080/0264041031000140374

Morgan, T. K., \& Giacobbi, P. R. (2006). Toward Two Grounded Theories of the Talent Development and Social Support Process of Highly Successful Collegiate Athletes. The Sport Psychologist, 20, 295-313. http://dx.doi.org/10.1123/tsp.20.3.295

Newcomb, M. D. (1990). Social Support and Personal Characteristics: A Developmental and Interactional Perspective. Journal of Social and Clinical Psychology, 9, 54-68. http://dx.doi.org/10.1521/jscp.1990.9.1.54

Nishida, Y. (2000). Diverse Life-Styles and Psychological Well-Being in Adult Women. The Japanese Journal of Educational Psychology, 48, 433-443.

Rees, T., \& Freeman, P. (2007). The Effects of Perceived and Received Support 5 on Self-Confidence. Journal of Sports Sciences, 25, 1057-1065. http://dx.doi.org/10.1080/02640410600982279

Rees, T., \& Hardy, L. (2000). An Investigation of the Social Support Experiences of High-Level Sports Performers. The Sport Psychologist, 14, 327-347. http://dx.doi.org/10.1123/tsp.14.4.327

Rees, T. (2007). Influence of Social Support on Athletes. In S. Jowett, \& D. Lavallee (Eds.), Social Psychology in Sport (pp. 224-231). London: Human Kinetics.

Rees, T., \& Freeman, P. (2010). Social Support and Performance in a Golf-Putting Experiment. The Sport Psychologist, 24, 333-348. http://dx.doi.org/10.1123/tsp.24.3.333

Reinhardt, J. P., Boerner, K., \& Horowitz, A. (2006). Good to Have but Not to Use: Differential Impact of Perceived and Received Support on Well-Being. Journal of Social and Personal Relationships, 23, 117-129. http://dx.doi.org/10.1177/0265407506060182

Sarason, B. R., Pierce, G. R., \& Sarason, I. G. (1990). Social Support: The Sense of Acceptance and the Role of Relationships. In B. R. Sarason, I. G. Sarason, \& G. R. Pierce (Eds.), Social Support: An Interactional View. Hoboken, NJ: John Wiley \& Sons.

Sarason, B. R., Sarason, I. G., \& Gurung, R. A. R. (2001). Close Personal Relationships and Health Outcomes: A Key to the Role of Social Support. In B. Sarason, \& S. Duck (Eds.), Personal Relationships: Implications for Clinical and Community Psychology (pp. 15-41). West Sussex, England: Wiley.

Tsuchiya, H. (2012). So-sharu sapo-to wo katsuyou shita supo-tsu kaunnserinngu.ba-n autoyobou no tame no chi-mu birudhinngu [Sport Counselling Utilising Social Support: Team Building for Burnout Prevention]. Tokyo: Kazama shobo. (In Japanese)

Van Yperen, N. W. (1998). Being an Sport Parent: Buffering the Effects of Your Talented Child's 
Poor Performance on His or Her Subjective Well-Being. International Journal of Sport Psychology, 29, 45-56.

Vazou, S., Ntoumanis, N., \& Duda, J. L. (2006). Predicting Young Athletes' Motivational Indices as a Function of Their Perceptions of the Coach- and Peer-Created Climate. Psychology of Sport and Exercise, 7, 215-233. http://dx.doi.org/10.1016/j.psychsport.2005.08.007

Weston, N. J. V., Thelwell, R. C., Bond, S., \& Hutching, N. V. (2009). Stress and Coping in Single-Handed Round-the-World Ocean Sailing. Journal of Applied Sport Psychology, 21, 460474. http://dx.doi.org/10.1080/10413200903232607

Yamauchi, T., Sudo, A., \& Tanno, Y. (2009). Reliability and Validity of the Japanese Version of the Brief Core Schema Scales. Japanese Journal of Psychology, 79, 498-505.

\section{Submit or recommend next manuscript to SCIRP and we will provide best service} for you:

Accepting pre-submission inquiries through Email, Facebook, LinkedIn, Twitter, etc. A wide selection of journals (inclusive of 9 subjects, more than 200 journals)

Providing 24-hour high-quality service

User-friendly online submission system

Fair and swift peer-review system

Efficient typesetting and proofreading procedure

Display of the result of downloads and visits, as well as the number of cited articles

Maximum dissemination of your research work

Submit your manuscript at: http://papersubmission.scirp.org/

Or contact psych@scirp.org 